\title{
GAIA Level 3 Assessment of Provider Initiated Preterm Delivery
}

National Cancer Institute

\section{Source}

National Cancer Institute. GAIA Level 3 Assessment of Provider Initiated Preterm

Delivery. NCI Thesaurus. Code C127952.

GAIA Level 3 Assessment of Provider-Initiated Preterm Delivery is defined by three criteria: first, the patient is determined to be between $240 / 7$ and 36 6/7 weeks gestation; second, from recall, the patient reports that there were no signs or symptoms of spontaneous onset of preterm labor; third, from recall, the patient reports that the healthcare provider indicated the need to induce labor or to perform a cesarean delivery between, resulting in preterm delivery. 